Coaches' cognitive appraisals

Stress appraisals of UK soccer academy coaches: an interpretative phenomenological analysis

Martin Dixon*

Department of Kinesiology

San Francisco State University, 1600 Holloway Avenue (Gym 101),

San Francisco,

CA 94132-4161,

USA.

Martin J. Turner

Centre for Sport, Health and Exercise Research

Staffordshire University,

Leek Road,

Stoke on Trent,

Staffs,

ST4 2DF,

United Kingdom.

*Corresponding author: mjdixon@sfsu.edu 


\title{
Stress appraisals of UK soccer academy coaches: an interpretative phenomenological
}

\section{analysis}

\begin{abstract}
Knowledge of how sports coaches appraise stress is sparse. This study investigates coaches' cognitive appraisals and explores the transactional nature of how coaches experience stress. Ten academy soccer coaches were interviewed using a semi-structured guide. Interpretative phenomenological analysis was employed to explore coaches' lived experiences of stressful situations. Coaches identified a range of situational demands including performance expectations, conflicting tasks, and managing relationships. Demands were evaluated in terms of perceived psychological danger. Coaches appraised their ability to meet these demands through resources such as self-efficacy, autonomy, and social support. Emotional and behavioural consequences of coaches' cognitive appraisals were also revealed. Findings provide a deeper understanding into the specific cognitive appraisals of coaches, revealing that determinants of stress appraisals are interdependent and complex.
\end{abstract}

Key words: Coaching, stress, cognitive appraisal, IPA, soccer academy

\section{Introduction}

Sports coaching is stressful, in part because coaches are subject to a vast array of stressors that can harm performance and psychological wellbeing (Fletcher and Scott 2010). Qualitative studies of elite coaches have revealed 182 distinct organizational and performance stressors (Thelwell et al. 2008), and 130 unique coaching stressors (Olusoga et al. 2009) respectively. Furthermore, a recent phenomenological analysis of Swedish elite soccer coaches described instances of coach burnout which emanated from a combination of issues related to the performance environment, a high workload, and family responsibilities (Lundkvist et al. 2012). 
Moreover, stress can negatively affect the psychological, physical, and behavioural responses of coaches, which can subsequently be projected onto athletes (Olusoga et al. 2010). For example, collegiate coaches from a range of sports have reported being tense, moody, more agitated and less approachable when stressed (Frey 2007). Additionally, in a survey study of 154 coaches, highly stressed coaches rated themselves as less active and less warm-hearted than those experiencing lower stress levels (Kellmann and Kallus 1994). However, whilst studies have identified the causal and consequential aspects of stress in sports coaching, there is a lack of research investigating how and why coaches experiencing similar stressors often respond in different ways (Fletcher and Scott 2010). In other words, research is yet to fully understand the transactional nature of coaching stress, where the coaching environment interacts with cognitive appraisals.

The negative wellbeing and performance outcomes of coaching stress have been established in the extant literature. However, it has been recognised for some time that human response to stressors is largely dependent on an individual's cognitive appraisals (Lazarus and Folkman 1984). According to Blascovich and Mendes’' (2000) biopsychosocial (BPS) model, individuals appraise stressful situations through primary evaluations of situational demands (e.g., perceptions of danger, uncertainty) and secondary appraisals of personal resources (e.g., knowledge and skills), resulting in either challenge or threat responses. Challenge is an adaptive motivational state which occurs when an individual experiences sufficient resources to meet situational demands. Conversely, threat is a maladaptive state which occurs when an individual experiences insufficient resources to meet situational demands (Blascovich and Mendes 2000). Therefore, individuals experiencing similar demands can exhibit very different responses, depending on their cognitive appraisals. The transactional notion of cognitive appraisals suggests that cognitive mediation between stressor and outcome is an important idea to examine in coaches. 
A more recent transactional theory, specific to the athletic domain, is the theory of challenge and threat states in athletes (TCTSA; Jones et al. 2009). The TCTSA posits that resource appraisals of self-efficacy, control, and goal orientation are the main determinants of challenge and threat states. Moreover, the TCTSA hypothesises that a challenge state will lead to superior performance compared to a threat state, which has been supported by emerging research in sport (e.g., Blascovich et al. 2004, Moore et al. 2012, Turner et al. 2013). Whilst the extant research pertains to athletes, the relationship between cognitive appraisals and performance may extend to coaches. Indeed, coaches should be considered 'performers' themselves, as they deal with difficult situations such as selection, tactics, and performance related issues whilst ensuring their own psychological and emotional states are at an optimal level (Thelwell et al. 2008). In a recent cross-sectional study investigating cognitive appraisals and coaching behaviour in youth soccer coaches, challenge appraisals were positively associated with social support, whilst threat appraisals were positively associated with autocratic behaviour and negatively associated with positive feedback (Dixon et al. 2017). Whilst preliminary findings identify relationships between cognitive appraisals and coaches' responses to stress, greater analysis into the appraisal process is needed to examine how and why coaches perceive and respond differently to common stressors.

Previous research examining coaching stress has focused exclusively on those working with collegiate or elite athletes, whilst academy coaches are underrepresented in stress literature. Professional soccer clubs in the UK incorporate talented players aged 8 to 16 into an associated academy, with recruitment and deselection occurring annually (Turner et al. 2014). Academy players may retain their place up to 16 years of age, before entering the professional ranks if they are one of the few selected (Harwood et al. 2010). A report into academy practices revealed that soccer academies often focus on winning matches rather than player development (Lewis 2007). Consequently, players experience pressure to perform, resulting in a fear of 
failure that can affect players' sporting performance and interpersonal behaviour (Sagar et al. 2010). Indeed, academy players experience a range of stressors such as making errors, selection, team performance, and criticism from coaches and parents (Reeves et al. 2009, 2011). Moreover, parents of academy players may experience stress due to unfamiliar coaching practices and the uncertainty of their son's retention in the academy (Harwood et al. 2010). Studies show that the soccer academy environment is stressful for players and parents, but little is known about academy coaches' experiences of stress.

The unique context of academy coaching involves attaining a balance between short-term performance and long-term development whilst managing relationships with both concerned parents and child athletes who themselves are experiencing unfamiliar pressures. Therefore, academy coaches' experiences of stress warrants further investigation. To the best of our knowledge the present study is the first to investigate coaches' cognitive appraisals of stress using a qualitative design, and the first to provide an in-depth analysis of the stressors experienced by academy coaches.

\section{Method}

\section{Design}

Interpretative phenomenological analysis (IPA) was used to examine in detail how participants made sense of their personal lived experiences (Smith 2004). The current study aimed to explore coaches' cognitive appraisals of stressful situations, which parallels IPA's concern with an individual's personal perception of an event, with cognition as a central analytic concern (Smith and Osborn 2008). Additionally, the idiographic foundations of IPA which is represented by detailed examination of individual cases prior to a cross-case analysis (Smith 2004) aligns with the idiosyncratic nature of stress appraisals (Blascovich and Mendes 2000). 
IPA is characterised by a 'double hermeneutic' approach as the participants make meaning of their experiences, and the researcher tries to decode that meaning to make sense of the participants’ meaning making (Smith and Osborn 2008, Pietkiewicz and Smith 2014).

\section{Participants and sampling}

Consistent with IPA research, purposeful sampling was utilised to obtain a homogenous sample (Smith and Osborn 2008). The individuals studied were able to purposefully inform an understanding of the central phenomenon in the study (Cresswell 2007) through their specific experiences of academy coaching. Participants were 10 male soccer coaches, ranging in age from 21-36 years $($ Mage $=27.9 \mathrm{SD}=4.74)$. Coaches had an average of 9.4 years $(\mathrm{SD}=3.5)$ total coaching experience with 5.2 years $(\mathrm{SD}=2.64)$ academy coaching experience. All of the coaches held the Union of European Football Associations (UEFA) B licence, whilst three coaches also held the UEFA A License.

Each participant was currently coaching at a UK soccer academy, the training environment operated by professional clubs for the development of youth players. Soccer academies in the UK comply with the Elite Player Performance Plan (EPPP), a strategy implemented by the English Premier League in 2012 which aims to improve the processes of youth development and increase the number and quality of home-grown players (Premier League 2011). In accordance with the EPPP, coaching quality is measured, in part, by player graduation rates and professional contracts awarded to academy players.

Participants coached an academy team ranging in age from 9 to 16 years. This involved a minimum three coaching sessions and one game per week, with those leading older age groups coaching more frequently. Seven of the coaches were employed full-time by their respective club, with some performing additional roles such as performance analysis and recruitment. 
Two part-time coaches worked outside of the club as physical education teachers, whilst another managed a community coaching program. All coaches had administrative responsibilities as part of their role.

\section{Data collection}

Having obtained institutional ethical approval, the researchers approached coaches via email communications through a club contact. Participants were informed of the nature of the study and the anonymity of their responses. Informed consent was obtained before conducting semistructured interviews. This method allowed the researchers to gain important information on the research phenomena whilst enabling flexibility for participants to report their thoughts and feelings (Sparkes and Smith 2014). Moreover, the semi-structured interview is the exemplary method for IPA as it facilitates rapport and allows the interview to go into novel areas (Smith and Osborn 2008). The interviewer (first author) has a background in coaching within professional soccer academies which facilitated rapport with the participants and helped to interpret and use jargon commonly exchanged during the interviews (Caron et al. 2013). Each participant was interviewed once in a private room at their respective clubs, with interviews lasting 40-70 minutes. Participants were given pseudonyms to maintain anonymity.

\section{Interview guide}

Whilst the current study did not aim to test any specific theory, theoretical frameworks were used to identify a target phenomenon (i.e., cognitive appraisals) that informed the interview guide and provided a comparative context for data analysis (Sandelowski 1993 cited Tamminen et al. 2013). The guide consisted of predetermined open-ended questions, with other questions emerging from the dialogue between interviewer and interviewee (DiCicco-Bloom and 
Crabtree 2006). An opening conversation about the participants’ professional background and current coaching roles developed a rapport. As recommended by Smith and Osborn (2008), questions started at a general level (e.g., are there any areas of your coaching role that you find demanding or stressful?), with more specific prompts used to elicit sufficient information (e.g., what are you telling yourself at that point?).

The interviews also consisted of a ranking exercise in which coaches identified stressful situations from their coaching practice and placed them in order of prominence. The purpose of the ranking exercise was to stimulate discussion around specific examples and yield pertinent information in light of other data gathered (Higgins and Moseley 2001). Information gained from the ranking exercise was used frame subsequent questions and to probe the participants on particular episodes, which are more likely to elicit verbalisations of cognitive processes (Ericsson and Simon 1980). Additionally, probes help to yield a thick and rich data set (Morse 2015).

\section{Data analysis}

The following process, recommended by Smith and Osborn (2008), was used to analyse the interviews. Firstly the transcript was read and reread closely, with the left-hand margin being used to annotate what was interesting or significant about the respondent's comments. When the entire transcript was annotated, the researcher returned to the beginning of the transcript and documented emerging theme titles. Here the initial notes were transformed into concise phrases which aimed to capture the essential quality of what was found in the text. The themes moved the response to a slightly higher level of abstraction and invoked more psychological terminology. This transformation of initial notes into themes was continued through the whole transcript with the same theme title used when similar themes emerged. The next stage 
involved a more analytical and theoretical ordering as some themes were clustered together whilst others emerged as superordinate concepts. Finally, a summary table consisting of coherently ordered themes was produced for the individual interview.

Consistent with the idiographic approach of IPA, insights produced as a result of intensive and detailed engagement with individual cases were only integrated in the later stages of analysis (Willig 2008). At this stage the researchers discerned repeating patterns and acknowledged new issues emerging through the transcripts, recognising ways in which accounts from participants were similar but also different (Smith and Osborn 2008). Summary tables for the individual interviews were integrated into an inclusive list of master themes (table 1.) to reflect the experiences of the group as a whole and obtain a more generalised understanding of the phenomenon (Willig 2008).

\section{Establishing rigor}

Adopting a relativist approach rather than universal criteria (Smith and McGannon 2017), rigor was attained through several strategies. That is, rather than assessing the quality of the study against a set of general, preordained criteria, we judge the paper through several techniques which are characteristic of phenomenological analysis and research on stress in sport (Sparkes and Smith 2009). The data analysis procedures outlined above were meticulously adhered to as we attempted to provide transparency regarding the process of sorting, choosing, and organizing the data (Tracy 2010). In addition, rigor was maintained through researcher triangulation, reflexivity, and thick description.

Authors one and two independently analysed the data before a comparison of findings and discussion of emergent themes. These discussions concerned how to interpret and categorise meaning units, and facilitated a greater richness of data through different relations to the 
psychological concepts (Lundkvist et al. 2012). In this form of analyst triangulation, the second author adopted the role of 'critical friend', encouraging reflection upon alternative explanations and interpretations as these emerged in relation to the data (Smith and McGannon 2017). In line with Nicholls et al. (2005), the critical friend helped uncover biases in the lead author's analytic approach and questioned how certain quotes reflected the participants' subjective experiences. Any disparities in the authors' interpretations were discussed through a process of rationalisation before a consensus was reached.

Whilst we acknowledge that our theoretical and practical knowledge cannot be completely separated from the interpretation, we reflected upon our role in producing these interpretations to maintain a commitment to grounding them in the participants' views (Larkin and Thompson 2012). Therefore, attempts were made to 'bracket' existing presuppositions during the initial analyses, in order to focus on what was actually presented in the transcripts (Biggerstaff and Thompson 2008). Subsequent analysis involved a 'dialogue' between the authors, our coded data and our psychological knowledge, leading to the development of a more interpretative account (Larkin and Thompson 2012). Having initially prioritised the participants' perspectives, the latter stages of analysis involved looking at the data through a psychological lens, interpreting it with the application of psychological concepts to illuminate the understanding of the research problem (Pietkiewicz and Smith 2014).

Recent criticisms of IPA highlight a lack of rigor in the way IPA researchers relate to hermeneutic practices (e.g., Giorgi 2011). Indeed, Chamberlain (2011) called for greater clarity around the critical connection between the analytic methods and the researcher's engagement in hermeneutic analysis. Thus, reflexivity and transparent data analysis procedures were especially pertinent in the current study. Consistent with our transparent approach, we invite the reader to see if our interpretations are clearly present in the data. To that end, thick 
descriptions of stress appraisal phenomenology are provided, so that readers may draw their own conclusions about the extracts (Tracy 2010).

Although steps were taken to ensure a rigorous research process, the limitations of IPA must be considered. Phenomenological analysis relies on the assumption that language provides participants with the necessary tools to capture the experience (Willig 2008). Indeed, whilst IPA has a theoretical commitment to the person as a cognitive being and assumes a chain of connection between people's talk and their thinking and emotional state, it must be acknowledged that this chain of connection is complicated as people struggle to express what they are thinking and feeling (Smith and Osborn 2008). As such, these limitations should be heeded when considering the data.

\section{Results}

The current study aimed to explore coaches' cognitive appraisals of stressful situations. Analysis of the interview transcripts revealed three superordinate themes; evaluation of situational demands, evaluation of coaches' personal resources, and coaches' emotional and behavioural responses.

\section{Demand appraisals}

This section reveals coaches' appraisals of the demands experienced. The appraisal process involved both the identification and evaluation of specific demands. These are categorised as performance, conflicting tasks, time pressures, managing relationships, uncertainty, and psychological danger.

\section{Performance}


Coaches reported pressure to attain good team performances and results in order to establish their reputation. Prioritising team performance and match outcome was perceived by coaches as counter-productive to their primary role of developing players for the long term.

[pressure] forces me to go into a bit more short termism... it forced me to be harder with the players I think, possibly more demanding in terms of their performances at the weekend... it also forced me to like, pick my best team every week... I probably took less risks with players and gave the players who were struggling less opportunities, when they needed that probably at times to fail really, you know, because that is part of the process as well. (David)

Everyone says the game, the wins, don't even matter, it's not about the winning, it's about developing players. Well that's easy to say if you're in a management role, but when you're a young aspiring coach coming in, you're getting judged on how your teams are playing. Generally, if teams are playing well they are winning. (Owen)

Coaches perceived that they were evaluated based on the performances of their players/teams. Indeed, coach performance appeared to be inextricably linked to player performance, with coaches assuming responsibility for team performance and results.

I don't like that [poor team performance] has happened, I don't like that its happened to the lads that I work with every day, it's a reflection of what we do back at the club, it's a reflection of what I do with them, it's a reflection of what people are thinking. Again, maybe paranoid thoughts, maybe no one is even thinking about that, but I am. (Karl)

Observation and evaluation of the coaches' personal coaching performance was also identified as a common situational demand. This occurred in formal settings when coaches were observed 
for professional development purposes, and in a more general sense, with coaches seeking acceptance in the academy environment.

Especially within the professional ranks, you think 'what do the senior coaches think of me as a coach? Did they see me as somebody who could go full-time for them? Do they see me as being capable of leading under eighteen’s sessions on my own?’ I think that can definitely be a stressor, you know, [gaining] that respect. (Matt)

In addition to player performance being salient to the coaches' professional growth, it was also important due to their personal investment in the players. Indeed, the prospect of releasing underperforming players was a potential stressor.

When you have to release the lads, I hated it, in terms of the build-up because you probably know deep down that weeks or even months before that they are underachieving... And I hated the conversation with parents when their lad is going to be released because it's subjective, it's your opinion, especially when the lad is thirteen, fourteen, they're going to take it badly. (Chris)

\section{Conflicting tasks}

Participants identified a range of potentially conflicting occupational tasks. In particular, coaches reported an increased administrative workload which they viewed as lacking relevance, with Daniel insisting 'the paperwork side has gone quite scary’. Several coaches reported that practical 'on the grass' coaching was not particularly demanding, but this primary job role was often obstructed by more peripheral tasks.

The most difficult time at [previous club] was probably the paperwork, it was time consuming and repetitive and borderline pointless most of the time. Dealing with the parents as a part-time member of staff was difficult... I would say the actual on the field stuff, that's what coaching is for me, so that's never been a problem. (Owen) 
I don't think coaching when you're out on the grass is stressful. That's enjoyable because that's what you do as a job, especially if you feel that you're good at the job and you plan well, the coaching side is the easy bit for me... I think it's your management of time and organisation off the pitch that's the most stressful bit. (Matt)

\section{Time pressures}

Related to the demanding range of tasks the coaches were expected to perform, time pressures were frequently reported. These demands were intensified when coaches had limited time to reflect on their practice, ultimately impeding their professional growth.

It is very time consuming, very demanding, so you know, in a 7 day week you often find you're sometimes working those 7 days, so it can be demanding on the role and you end up actually, rather than excelling in one area, you're sort of spread quite thin across other areas. (Brian)

You're being ask to do a lot, and at the time if you've got another job, there's other things going on all the time. The lack of time to plan for your session, to actually have timetabled planning and feedback for yourself, that’s hard to come by. (Matt)

\section{Managing relationships}

A frequently identified demand was managing relationships, not only with players, but with colleagues, managers, and parents. Working relationships with co-coaches were demanding, particularly when there was a difference in working practices. For example, when discussing a prominent stressor, Karl reported:

Staff not doing their job properly, not having high enough standards. A working relationship is difficult to manage or out of your control... at the end of the day we're in a business of producing professional footballers and dealing with peoples’ lives. I 
think when you're dealing with people's lives you take it seriously and make sure that you manage staff in that way where they hopefully take it, not as seriously necessarily as me, but they take it seriously to at least a level that's acceptable.

Coaches frequently reported managing relationships with players’ parents as demanding and potentially stressful, particularly if the child is 'underperforming.'

It's not just players that you're dealing with, its parents as well, and you know they just want the best for their kid, but sometimes they are looking through rose tinted glasses and they can’t always understand why you might want their child to do something, or the information you're actually saying, sometimes they don’t like to hear it. (Rob)

\section{Uncertainty}

When discussing potentially stressful situations, several coaches described instances of uncertainty. Perhaps surprising given the professional nature of academy coaching, uncertainty resulted from unexpected player non-attendance and changes to the facilities available.

When I plan a session for a certain number of kids, and then last minute that one doesn't turn up or whatever, that used to cause me stress because you wanted to put on the best session you could and suddenly... I didn't maybe have the tools to change my session at the last second, or adapt my session. So I just end up changing it to what suited rather than focusing on what I [initially] wanted to focus on. (Matt)

Uncertainty also emanated from unexpected match outcomes.

I remember losing in my fourth game... we were 1-nil up with 2 minutes to go at the local rivals thinking this is going to be the first win, and they're going to be absolutely buzzing ... and we go and concede two goals in the last two minutes... you know, absolute disaster. (Karl) 


\section{Psychological danger}

Further to identifying the situational demands encountered, coaches described their evaluations of these events. The sub-theme of psychological danger describes how coaches interpreted and experienced the aforementioned stressors. In particular, coaches revealed experiences of anxiety, pressure, and threats to self-esteem. For example, the following quote indicates how performance demands can be interpreted as pressure with potential damage to self-esteem.

I think the pressure and the stress comes from yourself and your own pride and the way in which you work and your own willingness to do really well, and the amount of work that you put in to make sure that you do well. That is the stress which I put on myself... I have a lot of internal pressure. (Karl)

Coaches also described experiences of worry, anxiety and pressure when discussing situational demands such as being observed by others and having difficult conversations with parents.

Every day you would have three people watching the session and almost pick it apart, and that can be a difficult process, particularly if you're not getting the right sort of feedback from it. I think that's where you can feel some of the pressure, if you're doing a session and you know you are getting critiqued. I think it's more when you don't know what they're are looking for as well. (David)

I hated that part of the job... that was the pressure there, talking with the parents before a release, so I would worry about it and get anxious about it. (Chris)

\section{Resource appraisals}


Coaches described a range of factors involved in the cognitive appraisals of their resources. These are categorised into self-efficacy, autonomy and control, achievement goals, and social support.

Self-efficacy

Resources related to self-efficacy were frequently reported. Coaches indicated that reflecting on previous successful performance led to greater self-efficacy, and subsequently a positive appraisal.

Every little fence I fell at it was like, it annoyed me more, frustrating me, and then eventually you prove to yourself 'no I can do this, I can do this', and every role you go into and you're successful you think 'yes I can do this', I'm getting more confident, more self-assured and therefore less and less stressed. (Rob)

Coaches also identified their relevant skills and knowledge. Skills included organisation and time management to meet the administrative demands, with practical coaching knowledge to deal with any 'on the grass' demands, such as uncertainty.

Well I think that I cope with [demands] quite well... I am quite good at managing my time. That's sort of one of my strengths that I've got so I can actually get things done when I need to. (Scott)

You have to sort of do it ad-hoc, off the cuff, which is fine you know, once you have been coaching for as long as I have, you can always think of a session to put on. (Owen)

\section{Autonomy and control}

The extent to which coaches perceived they were in control appeared to influence their appraisal of situational demands. Some coaches explained how the restrictive philosophies at 
certain clubs resulted in a lack of autonomy for the coaches, limiting their ability to respond to players' needs.

I think it definitely takes away some of the creativity and flexibility with [coaching], because you get bogged down in the process. You have to be seen to be doing certain things, a certain way. Even the way the session plans are done. So the session plans are generally done in advance, but not necessarily relevant to what you need to work on in that block of time, because they might have been planned three weeks ago, but there is something that has come up in a game that's really, really important. But you've got to be seen to be following the session plans, and it just doesn't leave you to be as flexible with things, and it's just becoming far too formal. (David)

The lack of autonomy was further exemplified through perceived threats to professional growth. Coaches discussed that continued employment depended on conformity to the club’s methods and practices, which often conflicted with the coaches’ own philosophies.

You want to make sure the players are progressing as a well-rounded player [but] you're being restricted in terms of game time, game play, and that kind of thing from the top, where you know the players need something a little bit different... I’ve heard stories of people who have been sacked for not doing it the right way and doing it their [own] way, so you know, I get on with it and do it. (Owen)

Coaches also recounted instances where perceived autonomy helped them meet situational demands. For example, when preparing to release a player, coaches reported being proactive in their 'chats' with parents so the release was less unexpected, and the likelihood of conflict was reduced. Coaches also described taking greater control of their coaching practices following a poor team performance or result. 
You just have to think 'well I'll make sure that the team is best prepared as they can be', and if it happens that it goes wrong, then I know I've given it my all, so I guess you put more effort in... You probably spend a little bit longer planning a session after a defeat rather than after a victory... whereas when you've won a couple of games, training is easy, the lads want to be there, are in a good mood and enjoy it more than after a defeat. So I guess you put a bit more focus into planning something to try and influence on the players. (Chris)

\section{Achievement goals}

Part of the coaches' appraisal process included their achievement goals, with examples of both approach goals (striving for competence) and avoidance goals (avoiding incompetence). More frequently, coaches demonstrated instances of approach focus which emphasised their efforts to develop players and improve team performance.

There’s no point going into a job thinking ‘do you know what I’ll just be average today.' I've read a quote that winning is getting better at what you do best every day. So that is what I try and do, I'm just driven inside to show people, through working with these players on a daily basis, my knowledge of the game and passion for the game, and also the pride in working to the best of what you know. (Karl)

Coaches reported fewer examples of avoidance goals. Chris discussed how he refrained from commenting during a parent meeting when a player was being released, choosing to leave the difficult conversation to a colleague. Other coaches adopted an avoidance orientation when faced with demands which held little intrinsic value. For example, David described his approach to writing match reports:

I make sure the kids get some relevant feedback, but you do the bare minimum. You just make sure the reports are completed, and if it means you give them a similar report 
to the one the week before, you do that, because, you know, I'm a part-time staff... You haven’t got time to be doing it. I was spending loads of time on these match reports and they never even looked at them. They just sit on the system.

\section{Social support}

An important resource for coaches when appraising demands was perceived support from others. Interviews revealed how support from colleagues, players and parents influenced coaches’ cognitive appraisals.

Each coach has a mentor so he'll come and watch me and give me feedback and stuff like that... it's done in a really good way in that sense because you're getting regular feedback after every session and it’s very constructive in the way it’s given. (Russell)

In addition to receiving support through guidance and advice, coaches frequently reported more tangible sources of social support to help the manage demands more effectively. In particular, coaches highlighted organisational support and man power as pertinent features in the appraisal process.

With [previous club] it was fantastic, you had an assistant. So sometimes you can pile a load, you know, certain amounts onto them. They can watch the individual stuff, while you run the session. At [current club] which was a huge surprise to me they don't have assistant coaches, which is unbelievable to be honest. (Owen)

Lack of support from an organisational point of view... from your own club. Whether it would be kit, whether it would be an assistant, whether it would be a meaningful feedback service. That for me would be the number one stressor. (Brian)

\section{Emotions and behaviours}


As coaches discussed their appraisals of demands and resources, they provided examples of emotional and behavioural responses. These are categorised into negative emotion, positive emotion, impact on coaching behaviour, giving social support, and 'masking' stress.

\section{Negative emotion}

The participants described experiencing negative emotions such as stress, anxiety, frustration, and disappointment. Instances of negative emotion typically emanated from coaches' assessments of team performance, anxiety around releasing underperforming players, and frustration with club processes.

Sometimes it's very hard to tear yourself away because you take it personal... if they have played poorly I feel I'm disappointed and not in a good mood about it so their performance reflects on me. I feel probably more than what the other staff maybe feel they should do so it's a personal issue. (Brian)

\section{Positive emotion}

Coaches also described examples of positive emotional responses. Coaches referred to feelings of enjoyment and reward when coaching 'on the grass'. Indeed, positive emotions were only reported in relation to practical coaching. For some coaches, practical coaching even helped to alleviate the stress which derived from other aspects of their job.

I always feel at home on the pitch, you know. The minute you're on the grass... I can just forget about all my worries, about all the major stressors that are causing me issues because when I walk on the pitch, it's kind of like this is, this is home to me, this is where I'm supposed to be. (Matt) 
Coaches' demand appraisals appeared to impact their coaching behaviour and performance in myriad ways. For example, Owen revealed that 'my face says more than what I actually say out loud'. Coaches reported instances of distancing themselves from players and colleagues following poor team performance. Additionally, some coaches revealed a tendency to use more autocratic behaviours and less appropriate pedagogical techniques when responding negatively to stress.

When I was at [previous club] and we lost, you couldn’t talk to me for 2 days. I would never talk on the journey back... I remember losing a game away at [competing club], it sounds ridiculous but I pride myself so much in the team’s performance, I don’t mean win, but playing well, playing the game the way I want it to be played.... And we had a nightmare, I think we lost about 6-nil. Worse defeat ever, and erm... 4 hour trip back and I didn't speak a word to anyone... And because of that nobody spoke a word to me. (Karl)

For me I go probably a bit more quiet because I know myself that if I get frustrated about a kid's performance or performance in training, I should be helping them... whether it would be Q and A or guided discovery or whatever. But if you're stressed you're very much going to go in an authoritarian manner, you're just going to go in and say 'that's not good enough.' So I just tend to be little bit more reserved and allow mistakes to pass, and try and just coach when I can, in the right manner... if you go in there and you're very authoritarian, like scold them in front of everybody, that's going to harm your relationship with them. There's definitely times when I have done that, and afterwards I have reflected and gone 'next time I should just stand there and allow it to just go.' (Matt)

\section{Giving social support}


Whilst coaches reported instances of becoming more distant and autocratic when experiencing stress, they also discussed examples of providing social support to others. In the context of poor team performance, some coaches reported giving more positive feedback and assurance, whilst also attempting to reduce the pressure on players.

We tried to keep the same principles in the session but we tried to take any pressure off the players, and tried to make it a little bit more fun, a little bit more light hearted, even though it was only two [defeats]... You try and give them confidence in the next game... We try to lighten the mood and make it more fun and enjoyable rather than just stress the importance of the results. (Chris)

In the very worst times, even when the worst moments felt bad... I completely flipped it around and only spoke about positives, so they were always left with hope, always left with positives. (Karl)

'Masking' stress

Coaches described how they adopted behaviours to mask any negative effects of stress. Chris described how he 'put on a show' when stressed, to ensure a positive working environment and to protect his players from any negative effects. Coaches also alluded to adopting confident behaviours during demanding situations. Furthermore, it was suggested that adopting positive behaviours to consciously mask the effects of stress was characteristic of a coach's professionalism.

I'm not saying everybody comes in and they are all happy and smiling, because people do have bad days and people do have issues at home and people do have other issues at work that they have to deal with, but I'm 99\% sure that the players wouldn't know if a member of staff had a personal issue that they were dealing with, or shouldn't know because of the body language or the way that they speak to people. (Brian) 


\section{Discussion}

The purposes of this study were to investigate stress appraisals of sports coaches and explore the transactional nature of how coaches experience stress. Results reveal that coaches identify and evaluate a range of situational demands and appraise their personal resources to meet these demands. Coaches also reported a variety of emotional and behavioural responses. In accordance with IPA methodology, the close textual analysis has been used to guide more formal theoretical connections in this discussion (Smith 2004). As a framework to interpret the findings of the present study, connections are made with challenge and threat theory, which addresses how people evaluate, react to, and behave in goal-relevant performance situations (Blascovich et al. 2003).

\section{Demand appraisals}

Coaches strived for competent performance to ensure continued professional growth. Coaches perceived that their performance was regularly evaluated by mentors and senior colleagues through direct observations of their coaching practice and judgements on their suitability to work within the academy environment. Coaches were also evaluated on player development, team performance, and match outcome. Results support previous research which found performance stressors divided between coaches’ own performance and that of their athletes (Thellwel et al. 2008). Interestingly, despite the developmental nature of their role, academy coaches experienced performance outcome pressures similar to those reported by collegiate and elite level coaches (e.g., Frey 2007, Olusoga et al. 2009). Consequently, coaches reported instances of 'short termism’ by prioritising results and performances over player development. Moreover, coaches felt their competency, and ultimately their professional growth, was judged 
through match outcome and player performance. In comparison to their own performance, coaches have less control over player performance and match outcome. Indeed, considering that soccer is characterised by unpredictable and complex situations occurring in the game (Rasmussen and Østergaard 2016), coaches only have finite influence on performance and results. Therefore, the performance others, or 'evaluation by association', may be an important consideration in the study of coaches’ cognitive appraisals. Moreover, coaches’ limited control over match outcomes could be a key determinant in their experiences of stress

Coaches identified the demands of conflicting tasks, time pressures, relationship management, and uncertainty. Whilst these have been reported as stressors amongst sports coaches in previous studies (Frey 2007, Olusoga et al. 2009), the current study offers further insight into the evaluations of such demands. When discussing their appraisals of demanding situations, coaches reported experiences of psychological danger, such as pressure, anxiety, and threats to self-esteem. Common scenarios that invoked psychological danger included difficult conversations with parents, observation from senior colleagues, and a damaged reputation following poor performances or results. Indeed, findings reveal that team performance and match outcome can potentially impact coaches' self-esteem. Coaches' belief that they can influence team performance is natural, given their job role. However, considering the myriad factors which can impact player performance and match outcome, perceptions of being fundamentally responsible for team performance could heighten feelings of psychological danger.

\section{Resource appraisals}

Coaches' perceptions of their knowledge and skills emerged as important facets of their cognitive appraisals. Beliefs about their organisational skills and practical coaching abilities, 
through reflection on previous successful experiences, promoted coaches' self-efficacy. According to the theory of challenge and threat states in athletes, self-efficacy is a key determinant of the appraisal process, with higher self-efficacy enhancing an individual's perceived resources (Jones et al. 2009). Therefore, how coaches reflect on their attributes and previous experiences could play a key role in determining how they experience stress. Closely related to self-efficacy, coaches in the current study discussed their perceptions of control and described how restrictive organisational practices could foster negative appraisals. Thus, coaches not only needed to believe they have the knowledge and skills to meet a demanding situation, they also needed to feel a degree of autonomy to use their abilities effectively.

Achievement goals also emerged as an important factor in coaches' resource appraisals. Approach goals were particularly evident through 'on the grass' coaching scenarios, where coaches highlighted their motivation to develop players and influence team performance. Coaches might invest more time and effort into their practical coaching as they feel it is the most rewarding aspect of the job, and possibly the area subject to greatest evaluation. In contrast, examples of avoidance goals were associated with parent meetings and administrative tasks. Therefore, coaches tended to adopt an avoidance orientation towards situational demands which they perceived to be less rewarding and less likely to be evaluated by others.

Social support emerged as a significant element in the appraisal process. Coaches emphasised the importance of organisational support through man power and facilities, and also highlighted guidance from mentors. In light of Rees and Hardy’s (2000) four dimensions of social support in sport, coaches in the current study tended to value tangible and informational forms of social support over emotional and esteem. Tangible support, defined as 'concrete instrumental assistance, in which a person in a stressful situation is given the necessary resources to cope with the stressful event' (Cutrona and Russell, 1990 p. 322; cited Rees and Hardy 2000), appeared the most prominent form of support, possibly because it reduces the perceived 
demand. Indeed, the presence of an object or person in a performance situation may increase situational familiarity and decrease the appraisal of danger (Blascovich and Mendes 2000). Social support is not a determinant of cognitive appraisals in the TCTSA. However, current findings suggest that tangible and informational sources might play an important role in coaches’ stress appraisals.

\section{Emotions and behaviours}

Although the primary aim of the study was to investigate coaches' cognitive appraisals, discussion of their emotional and behavioural responses are of practical and theoretical significance. Coaches reported positive emotions such as enjoyment when working with players 'on the grass'. This may be due to practical coaching being the most motivating and satisfying aspect of their job, in comparison to mundane administration tasks and managing complex working relationships. Additionally, exposure to green spaces is associated with lower stress (Roe et al. 2013) therefore the physical environment may also be a determinant in how coaches experience stress. Coaches also reported negative emotions such as stress, anxiety, and frustration. Consequent behavioural responses included withdrawing from interactions, being more autocratic, and offering a limited range of pedagogical methods. Similarly, challenge appraisals amongst coaches have been positively associated with social support, and threat appraisals positively associated with autocratic behaviour and negatively associated with positive feedback (Dixon et al. 2017). Demand and resource appraisals determine an individual's emotional and physiological responses, which subsequently impact performance through consequences such as cognitive functioning (Jones et al. 2009). Current findings provide further support to the notion that cognitive appraisals of stress can impact coaches' behaviour, interactions, and pedagogies. 
Interestingly, coaches showed an awareness that stress could negatively impact their behaviour and consciously adopted more 'positive' coaching behaviours in stressful situations. Findings support previous research which found that coaches might adopt controlling behaviours to 'mask' or hide their stress so their athletes remain unaffected (Olusoga et al. 2010). However, the current findings go further to suggest that when coaches are experiencing stress themselves, they consciously offer more social support through positive feedback and assurance.

\section{Limitations and future research}

Before discussing the current study's contribution to sports coaching and stress appraisal literature, some limitations must be addressed. Firstly, findings from ten male soccer coaches are not applicable to all coaching contexts, as gender and years of coaching experience are predictive of stress appraisals (Kelley and Gill 1993). Secondly, although findings on behavioural responses have yielded useful information for coaches and practitioners, these responses cannot be directly attributed to the appraisal process, given the myriad factors which

can impact coaches' behaviour such as their education, experience as an athlete, and hours of coaching per week (Rodgers et al. 2007). Therefore, future research should investigate coaches' cognitive appraisals and responses by more directly analysing coaching behaviour in response to demanding situations.

The study of stress appraisals through self-report methods highlights another limitation. Blascovich and Mendes (2000) asserted that although self-report methods can provide important information, more room for error exists when individuals attempt to capture appraisals via self-report rather than physiologically. Whilst the researchers acknowledge this point, the current study reveals how the determinants of cognitive appraisals are complex and interdependent. For example, tangible social support is not just a determinant of resource 
appraisal in and of itself, but could also reduce perceived demand, and enhance perceptions of self-efficacy and control, thereby influencing other determinants. Similarly, a perceived lack of autonomy due to restrictive organisational practices might influence achievement goals by promoting an avoidance orientation, whilst also reducing perceived social support. Thus, rather than the formulaic view of challenge and threat, which is characteristic of quantitative research, findings from the current study suggest a more interactive nature of cognitive appraisals. Whilst the current study does not provide a complete representation of the appraisal process, it offers valuable insights and can be used to provide convergent evidence of stress appraisal phenomenology. Understanding coaches' cognitive appraisals provides a foundation for future research to explore specific methods of promoting challenge states to optimise coach performance and wellbeing.

\section{Conclusion}

This study is the first to provide an in depth qualitative investigation into coaches' cognitive appraisals of stress. Findings offer some useful additions to the extant coaching stress literature. Firstly, further to previous research on parents and players in academy settings, coaches are subject to a range of stressors, revealing experiences of pressure, anxiety, and damage to selfesteem. Secondly, prominent features of coaches' resource appraisals included tangible forms of social support, efficacy beliefs established through reflection, and perceptions of control. Additionally, the current investigation reveals some important considerations for the study of stress appraisals. Findings highlight that 'evaluation by association' could be an important determinant of the appraisal process. To our knowledge existing research has yet to consider the performance of others as a dimension of the stress appraisal process. Lastly, the findings 
add to stress appraisal literature by highlighting the interdependent and interactive nature of appraisal determinants.

A clearer understanding of the stress process in coaches, including cognitive appraisals, may enable coaches, and psychologists working with coaches, to manage stress more effectively (e.g., Turner and Jones 2014). That is, in line with past research it is possible to influence cognitive appraisals through the use of instructional sets (Turner et al. 2014), imagery (Williams and Cumming 2012), and reappraisal (Jamieson et al. 2012). Therefore, a deeper understanding of coaches’ cognitive appraisals can help to tailor specific interventions.

\section{References}

Biggerstaff, D. and Thompson, A.R., 2008. Interpretative phenomenological analysis (IPA): a qualitative methodology of choice in healthcare research. Qualitative research in psychology, 5 (3), 214-224.

Blascovich, J. and Mendes, W.B., 2000. Challenge and threat appraisals: the role of affective cues. In: J.P. Forgas, ed. Feeling and thinking: the role of affect in social cognition. Paris: Cambridge University Press, 59-82.

Blascovich, J., Mendes, W.B., Tomaka, J., Salomon, K., and Seery, M., 2003. The robust nature of the biopsychosocial model challenge and threat: a reply to Wright and Kirby. Personality and social psychology review, 7 (3), 234-243.

Blascovich, J., Seery, M.D., Mugridge, C.A., Norris, R.K., and Weisbuch, M., 2004. Predicting athletic performance from cardiovascular indexes of challenge and threat. Journal of experimental social psychology, 40 (5), 683-688. 
Caron, J.G., Bloom, G.A., Johnston, K.M., and Sabiston, C.M., 2013. Effects of multiple concussions on retired National Hockey League players. Journal of sport and exercise psychology, 35 (2), 168-179.

Chamberlain, K., 2011. Troubling methodology. Health psychology review, 5 (1), 48-54.

Cresswell, J.W., 2007. Qualitative inquiry and research design. 2nd ed. London: Sage.

Cutrona, C.E. and Russell, D.W., 1990. Type of social support and specific stress: toward a theory of optimal matching. In B.R. Sarason, I.G. Sarason and G.R. Pierce, eds. Social support: an interactional view. New York, NY: Wiley, 319-366.

DiCicco-Bloom, B. and Crabtree, B.F., 2006. The qualitative research interview. Medical education, 40 (4), 314-321.

Dixon, M., Turner, M.J., and Gillman, J., 2017. Examining the relationships between challenge and threat cognitive appraisals and coaching behaviours in football coaches. Journal of sports sciences, 35 (24), 2446-2452.

Ericsson, K.A. and Simon, H.A., 1980. Verbal reports as data. Psychological review, 87 (3), $215-251$.

Fletcher, D. and Scott, M., 2010. Psychological stress in sports coaches: a review of concepts, research, and practice. Journal of sports sciences, 28 (2), 127-137.

Frey, M., 2007. College coaches' experiences with stress - 'problem solvers' have problems, too. The sport psychologist, 21 (1), 38-57.

Giorgi, A., 2011. IPA and science: a response to Jonathan Smith. Journal of phenomenological psychology, 42 (2), 196-216. 
Harwood, C., Drew, A., and Knight, C.J., 2010. Parental stressors in professional youth football academies: a qualitative investigation of specialising stage parents. Qualitative research in sport and exercise, 2 (1), 39-55.

Higgins, S. and Moseley, D., 2001. Teachers' thinking about information and communications technology and learning: beliefs and outcomes. Teacher development, 5 (2), 191-210.

Jamieson, J. P., Nock, M. K., and Mendes, W. B., 2012. Mind over matter: Reappraising physiological arousal improves cardiovascular responses to stress. Journal of experimental psychology: General, 141 (3), 417-422.

Jones, M., Meijen, C., McCarthy, P.J., and Sheffield, D., 2009. A theory of challenge and threat states in athletes. International review of sport and exercise psychology, 2 (2), 161180.

Kelley, B.C. and Gill, D.L., 1993. An examination of personal/situational variables, stress appraisal, and burnout in collegiate teacher-coaches. Research quarterly for exercise and sport, 64 (1), 94-102.

Kellmann, M. and Kallus, K.W., 1994. Interrelation between stress and coaches' behavior during rest periods. Perceptual and motor skills, 79 (1), 207-210.

Larkin, M. and Thompson, A., 2012. Interpretative phenomenological analysis. In: A. Thompson and D. Harper, eds. Qualitative research methods in mental health and psychotherapy: a guide for students and practitioners. Oxford: John Wiley \& Sons, 99116.

Lazarus, R.S. and Folkman, S., 1984. Stress, appraisal and coping. New York, NY: Springer.

Lewis, R., 2007. The Lewis review: a review of young player development in professional football [online]. Available from 
http://assets.ngin.com/attachments/document/0001/3697/ReviewofYoungPlayerDevel opment1_1_.pdf [Accessed 19 November 2017]

Lundkvist, E., Gustafsson H., Hjälm, S., and Hassmén, P., 2012. An interpretative phenomenological analysis of burnout and recovery in elite soccer coaches. Qualitative research in sport, exercise and health, 4 (3), 400-419.

Moore, J.L., Vine, S.J., Wilson, M.R., and Freeman, P., 2012. The effect of challenge and threat states on performance: an examination of potential mechanisms. Psychophysiology, 49 (10), $1417-1425$.

Morse, J.M., 2015. Critical analysis of strategies for determining rigor in qualitative inquiry. Qualitative health research, 25 (9), 1212-1222.

Nicholls, A.R., Holt, N.L., and Polman, R.C.J., 2005. A phenomenological analysis of coping effectiveness in golf. The sport psychologist, 19 (2), 111-130.

Olusoga, P., Butt, J., Hays, K., and Maynard, I.W., 2009. Stress in elite sports coaching: identifying stressors. Journal of applied sport psychology, 21 (4), 442-459.

Olusoga, P., Butt, J., Maynard, I., and Hays, K., 2010. Stress and coping: a study of world class coaches. Journal of applied sport psychology, 22 (3), 274-293.

Pietkiewicz, I. and Smith, J.A., 2014. A practical guide to using interpretative phenomenological analysis in qualitative research psychology. Psychological journal, 20 (1), 7-14.

Premier League. 2011. Elite player performance plan. London: Premier League.

Rasmussen, L.J.T. and Østergaard, L.D., 2016. The creative soccer platform: new strategies for stimulating creativity in organized youth soccer practice. Journal of physical education, recreation \& dance, 87 (7), 9-19. 
Rees, T. and Hardy, L., 2000. An examination of the social support experiences of high level sports performers. The sport psychologist, 14 (4), 327-347.

Reeves, C., Nicholls, A. R., and McKenna, J. 2009. Stressors and coping strategies among early and middle adolescent premier league academy soccer players: differences according to age. Journal of applied sport psychology, 21 (1), 31- 48.

Reeves, C.W., Nicholls, A.R., and McKenna, J., 2011. Longitudinal analysis of stressors, perceived control, coping and coping effectiveness among early and middle adolescent soccer players. International journal of sport psychology, 42 (2), 186-203.

Rodgers, W., Reade, I., and Hall, C., 2007. Factors that influence coaches' use of sound coaching practices. International journal of sports science \& coaching, 2 (2), 155-170.

Roe, J.J., Ward Thompson, C., Aspinall, P.A., Brewer, M.J., Duff, E.I., Miller, D., Mitchell, R., and Clow, A., 2013. Green space and stress: evidence from cortisol measures in deprived urban communities. International journal of environmental research and public health, 10 (9), 4086-4103.

Sagar, S.S., Busch, B, K., and Jowett, S., 2010. Success and failure, fear of failure, and coping responses of adolescent academy football players. Journal of applied sport psychology, 22 (2), 213-230.

Sandelowski, M., 1993. Theory unmasked: the uses and guises of theory in qualitative research. Research in nursing and health, 16 (3), 213-218.

Smith, B., and McGannon, K. R., 2017. Developing rigor in qualitative research: problems and opportunities within sport and exercise psychology. International review of sport and exercise psychology, 1-21, published online 14 May 2017, doi:10.1080/1750984X.2017.1317357 
Smith, J.A., 2004. Reflecting on the development of interpretative phenomenological analysis and its contribution to qualitative research in psychology. Qualitative research in psychology, 1 (1), 39-54.

Smith, J.A. and Osborn, M., 2008. Interpretative phenomenological analysis. In: J. Smith, ed. Qualitative psychology: a practical guide to research methods. 2nd ed. London: Sage, 53-80.

Sparkes, A.C. and Smith, B., 2009. Judging the quality of qualitative inquiry: Criteriology and relativism in action. Psychology of sport and exercise, 10 (5), 491-497.

Sparkes, A.C. and Smith, B., 2014. Qualitative research methods in sport, exercise and health. New York, NY: Routledge.

Tamminen, K.A., Holt, N.L., and Neely, K.C., 2013. Exploring adversity and the potential for growth among elite female athletes. Psychology of sport and exercise, 14 (1), 28-36.

Thelwell, R.C., Weston, N.J.V., Greenlees, I.A., and Hutchings, N., 2008. Stressors in elite sport: a coach perspective. Journal of sports sciences, 26 (9), 905-918.

Tracy, S. J., 2010. Qualitative quality: eight "big-tent” criteria for excellent qualitative research. Qualitative inquiry, 16 (10), 837-851.

Turner, M. J. and Jones, M. V., 2014. Stress, emotions and athletes' positive adaptation to sport: Contributes from a transactional perspective. In: A.R. Gomes, R. Resende, and A, Albuquerque, eds. Positive human functioning from a multidimensional perspective. Hauppauge, NY: Nova Science.

Turner, M. J., Jones, M. V., Sheffield, D., Barker, J. B., and Coffee, P., 2014. Manipulating cardiovascular indices of challenge and threat states while maintaining task importance. Psychophysiology, 94, 9-18. 
Turner, M.J., Jones, M.V., Sheffield, D., Slater, M.J., Barker, J.B., and Bell, J.J., 2013. Who thrives under pressure? Predicting the performance of elite academy cricketers using the cardiovascular indicators of challenge and threat states. Journal of sport and exercise psychology, 35, 387-397.

Turner, M.J., Slater, M.J., and Barker, J.B., 2014. Not the end of the world: the effects of rational-emotive behavior therapy (REBT) on irrational beliefs in elite soccer academy athletes. Journal of applied sport psychology, 26(2), 144-156.

Williams, S. E., and Cumming, J., 2012. Challenge vs. threat imagery: Investigating the effect of using imagery to manipulate cognitive appraisal of a dart throwing task. Sport \& exercise psychology review, 8, 4-21.

Willig, C., 2008. Introducing qualitative research in psychology. 2nd ed. New York, NY: Open University Press. 